\title{
SOME PHASES OF THE DISPENSARY PROBLEM
}

"Of all the subjects with which the charity worker has to deal," said Dr. Silas F. Hallock in a recent address, "hospital charity is one of the most important. When we stop to consider the large proportion of cases which come to us for relief, and of which sickness is the chief and determining cause of financial distress-and in many more it is the contributing cause-we can readily see its importance. Then again when we consider how much sickness is to be traced to the ignorance of the masses as to the simplest rules of hygiene or proper preparation and cooking of food, we see that our work is not only curative but educational and preventive."

Hospital charity may be separated into two main divisions: treatment in cases where the patient occupies a bed and remains in the hospital during the entire duration of the illness, and outdoor relief, where the patient comes to the hospital or dispensary for treatment and advice, but lives at home and very often continues the usual round of daily duties. It is with the latter phase of medical charity that we are now concerned.

The subject is an old one, and for generations the uses and abuses of the dispensary have been discussed both by the medical profession and the laity. That there is and always has been need of improvement in dispensary service must be admitted; that much unnecessary obloquy rests upon the dispensary and its work there is also but little doubt. Charitable work of all sorts is more and more seeking to prevent rather than to cure destitution. "It is better to have a fence at the top of a precipice than an ambulance at the bottom; better to prevent a man from going down than to try to raise him when he has fallen." It is in this way that the dispensary serves a particularly useful purpose. Preventive medicine occupies an increasingly important place in the work of the medical profession, and dispensary treatment endeavors to check the disease before it has become so serious that it involves the train of hardships consequent upon giving up work.

An English observer says:

"At present our most highly equipped-and therefore most formidable[424] 
competitors are our kinsmen across the Atlantic. America is commercially formidable, not merely because of her gigantic enterprises and almost illimitable resources, but because, as recent investigations have shown, her workers are better nourished and possess a relatively higher efficiency."

Industrial success cannot be secured by any body of people unless the public health is maintained. The functions of municipal government deal largely with questions of good housekeeping which affect the people as a whole. The effects of a good or bad water supply are instantly reflected in the commercial prosperity or troubles of a city. Hamburg, with unfiltered water, was once the scene of a constant scourge of disease. Supplied fron the same sources, but with its water purified before reaching the consumer, it is now a healthful city. One of the most serious results of bad municipal government in this country is its invariable effect on the health as well as the morals of the community. Clean streets, proper building laws and public sanitation all have a direct influence on the public health. The first duty of the community is to keep the citizen well, to prevent the danger of illness, and, in case of accident and disease, to return the wage-earner as soon as possible to the ranks. This should be done so as to interfere as little as may be with his productiveness and consequently, where possible, treatment should be commenced at the outset of the disease in a dispensary or the out-patient department of some hospital, in order that the sufferer may keep at work and retain his means of livelihood. Where this is not possible, the patient has to be cared for in the hospital ward. We often forget what this means where the family is barely able to maintain itself on the combined earnings of all its members.

Another point which is too often lost sight of is the difference in cost between walking cases and in-patients. Sir Henry Burdett states:

"The cost of treating I,000 out-patients is about equal to the expenditure upon one constantly occupied bed, provided the administration of the institution in question is conducted with reasonable efficiency."

The figures for England, while hardly applying to this country, as the dispensary cases there do not receive as costly treatment as here, yet give a general idea of the great difference in cost between the two classes of patients.

1 "Poverty, A Study of Town Life," by B. Seebohm Rowntree.

${ }^{2}$ Burdett's "Hospitals and Charities." London, 1903. 
The most often discussed point in connection with dispensaries is the abuse of their facilities by those who are able to pay a physician. It is generally agreed that all those below the "poverty line," and a large number whose earnings are barely more than sufficient to keep the family together, provided the health of all is good, are fit subjects for the dispensary's care. Unfortunately there are no figures to give even an approximate idea of what proportion of the population this may be in our great cities. Mr. Rowntree, in his study of poverty in York, England, writes:

"Nearly thirty per cent of the population are living in poverty and are ill-housed, ill-clothed and under-fed. So long as this state of things continues a low average of efficiency among the wage-earning classes is inevitable."

He further states:

"We have been accustomed to look upon the poverty in London as exceptional, but when the result of a careful investigation shows that the proportion of poverty in London is practically equalled in what may be regarded as a typical provincial town, we are faced by the startling probability that from 25 to 30 per cent of the population of the United Kingdom are living in poverty."

In a study of social conditions in the southeastern end of Boston, it is stated that "about thirty per cent. of West End people, and about forty per cent. of North End people, are below the line of poverty as set by Charles Booth in his London studies." 3 These figures refer only to congested districts in Boston; for the whole city the proportion would, of course, be far lower. In this country, the number of persons living in poverty is much less than in England. Miss Richmond, General Secretary of the Philadelphia Society for Organizing Charity, says:

"My own opinion is that we have little or none of the hereditary pauperism of England, and that the percentage (in this country) should be much lower-say not more than a third as much."

The fact remains, however, that a considerable proportion of our population is living from hand-to-mouth, and is not in a fit position to face the complications which disease and loss of occupation bring. Before one can measure the extent to which dispensary privileges are abused by the patients, it must be discovered what proportion of the population is actually unable to pay anything for the service of a physician.

"Americans in Process-A Settlement Study." Boston, igo2. 
If ro per cent. of the population of our larger cities are below the "poverty line," and possibly half as many again are so little more than self-sustaining that they cannot afford to pay a physician in time of illness-then among the remaining dispensary attenders we must include those who are able to pay, but very sensibly prefer the free services of skilled dispensary physicians to the care of often less capable practitioners whose fees are within their reach.

Other circumstances besides poverty may also be considered proper reasons for attendance at dispensaries. Chief of these is the educational value to the student of medicine which comes from studying at first hand the cases which present themselves at a dispensary. In other words, it is often to the advantage of the community that persons able to pay a small fee should be treated without further return than their willingness to serve as subjects for demonstration for classes of medical students. This is particularly true in regard to special diseases where difficulty is found by the teacher in securing adequate material. It is a strong argument for confining free dispensaries to teaching institutions. There is, moreover, less danger of slovenly treatment in a dispensary used for teaching. As Dr. W. W. Keen says: "Students are the best whip and spur I know."

A physician connected with a medical school in one of our smaller cities writes:

"As yet we have not to complain of any abuses. The hospital with which I am connected has only an out-patient service for the eye and the nose and throat, as it was felt to be an injustice to the younger general practitioners to foster a general out-patient service. But for instruction there must be ambulant patients, especially as the younger practitioners will find among such their chief clientele later."

The results of a recent investigation of the dispensaries in Philadelphia ${ }^{4}$ may prove of value as giving in concrete form a view of the situation as it exists to a greater or less extent in most of our large cities. In order to secure the necessary data, letters were sent to a large number of physicians, and at the same time a question blank was sent to each of the dispensaries in Philadelphia, asking for detailed information. The results of this investigation showed that there were 6r dispensaries in Philadelphia devoted to the relief of the sick and injured. More than half of these were connected with hos-

4."The Dispensary Problem in Philadelphia-A Report made to the Hospital Association of Philadelphia, October 28, r $903 . "$ 
pitals. In 42 of the dispensaries under consideration, 305,980 patients were treated during 1902 , or 238 cases for each $I, 000$ of the population. An investigation made in 1880 showed that at that time 159 persons were receiving treatment for each I, Ooo of the population. In twenty-three years the percentage had risen from i 5.9 to 23.8. In New York, 876,070 patients were treated during I900, or 254 for each 1,000 of the population. While the statistics do not include all of the Philadelphia dispensaries, they are sufficiently accurate to give a close idea of the total amount of work done. The number of cases treated would undoubtedly have been raised a few thousand had complete statistics been obtained, but this increase would probably be offset by the number of eases which appear more than once in the figures which have been secured. It can, in a general way, be stated that more than one-fifth of the populatjon is now receiving free treatment at the dispensaries in Philadelphia. There are over 800 physicians connected with these institutions, almost all of whom give their services without receiving any direct compensation. That the indirect return is fully worth the time expended is shown by the competition to secure dispensary positions, particularly of the higher grade.

A study of the superintendents' answers gives the impression that there is little uniformity in the methods of management and that there must be considerable carelessness in the carrying out of these methods. It has been impossible to get an accurate idea as to the cost of maintenance of the dispensaries. The figures given vary from one-half cent to $\$ 1.32 \frac{1}{2}$ for each patient treated. As most of the dispensaries are connected with hospitals, and as these institutions as a rule do not separate the expenditures for the in-and out-patient departments, the figures given must in most cases be simply the result of guesswork. The difference would, however, be partly accounted for were the items known which had been included in the figures. The institutions reporting the higher costs have undoubtedly included a proportionate amount of the total outlay for maintenance of plant, interest charges, heat, light, wages and other expenditures of this nature, in addition to the actual cost of materials used. The institutions giving the lower figures cannot include anything but the actual value of the materials dispensed. In most of the dispensaries under consideration no effort is made to [428] 
increase the number of patients, and but one-third use their cases for teaching purposes. Less than one-third attempt to prevent imposition by patients able to pay. Of these the larger number try to regulate the matter by simply questioning the patient. Where patients are able to pay, the majority report that they are referred to the office of a physician. The indirect gain which some dispensary physicians are able to secure is shown by the practice at several of the dispensaries of permitting them to refer cases to their own offices.

A large proportion of the physicians who were consulted agree that the chief abuse of the dispensary is that patients are treated who are able to pay a physician for his services. As to the other abuses, there is no unanimity of opinion, although many which are noted are undoubtedly true. The abuse on the part of the doctors mentioned by the largest number of physicians, is that patients are not carefully treated in the dispensary. This is a natural result of handling large numbers of people in a limited amount of time, and is an undoubted fact. A problen which was not enlarged on by the doctors, is that of the many patients applying for free treatment at our dispensaries are persons who have exhausted their resources in paying a doctor and are forced to seek the aid of these institutions to rectify the results of improper treatment.

In Philadelphia the problem presented is that of sixty-one dispensaries, having little or nothing in common, competing with each other more or less directly, and all of them anxious to show large returns in the amount of work done. Connected with them are about 28 per cent. of the physicians practicing in Philadelphia, and yet the majority of doctors feel, rightly or wrongly, that dispensaries are fostering abuse and depriving them of fees justly theirs. They tell us that the district physicians, who are paid by the city, should care for the indigent poor, that competition should be eliminated and means taken to prevent imposition, and yet they are apparently unwilling or unable to take any steps to alter existing conditions. A careful scrutiny of the answers received from both physicians and superintendents at the time of the investigation made last summer, leads to the conclusion that, while the chief abuse is the application for treatment by those who are able to pay, the management of our 
dispensaries and the physicians connected with them are also open to criticism.

The State of New York has been the first to recognize the necessity for regulating dispensary practice. Its law, which has now been in effect for more than three years, has already shown good results. It has acted as a check to indiscriminate dispensary attendance, the increase in the number of patients since the enactment of the law having been proportionately less than the increase in the population during the same period. ${ }^{5}$ The law defines the purpose of dispensaries, provides that they shall be licensed by the State Board of Charities, and gives rules and regulations for their operation. In addition, the State Board of Charities is given power to visit and inspect licensed dispensaries and, after due notice, to revoke these licenses in case the public interest should demand such action. In accordance with the terms of the act, the New York State Board of Charities has adopted a simple but effective set of rules requiring that in each dispensary there shall be posted a public notice showing that the dispensary has been duly licensed under the laws of the State, and providing for a registrar to supervise the work of the dispensary and to make and preserve all records, receive applicants and enforce the rules and regulations. All emergency cases must be admitted and receive prompt care and treatment. Every applicant who is deemed poor and needy is to be treated. Where there is a question as to the patient's ability to pay, the registrar is to make an investigation, the results of which are filed among the permanent records of the dispensary. At the same time the patient is required to sign a statement in a form approved by the Board of Charities. It is a misdemeanor to receive treatment on false representations. The Board also provides for the appointment of a matron, excludes the treatment of contagious diseases, directs that cases shall not be used for teaching purposes without consent being obtained, and defines the duties of the apothecary and provides for sanitary inspection and the arrangements and equipment of the dispensary. Legal enactment is undoubtedly a step in the right direction, and where the State Board of Health is a liberal-minded and progressive body much can be done to prevent abuse and increase the efficiency of these institutions. The provision making it a misdemeanor to receive treatment on false

5 "Dispensary Law Effective," Stephen Smith, M. D., Charities, August 29, 1903.

[430] 
pretences is in itself a safeguard, as well-to-do people, who would unblushingly demand the services of a dispensary physician, might be deterred by knowing that discovery of their imposition would lead to prosecution and punishment. Another value of legal control is found in the fact that inspection can be made by a competent branch of the State government, thus making it possible to require a higher standard of efficiency than would be possible where no such control exists.

At the present time, too little thought is given to the equipment and detail management of the dispensaries, particularly where they are not connected with medical schools. It is just as important to keep accurate and scientific records of the work done in a dispensary as it is in a research laboratory. The recent adoption of more accurate systems of records by some of the leading institutions in this country is a hopeful sign and should help to raise the standard of efficiency. It will also aid in ferreting out the patients addicted to the so-called "dispensary habit," who drift from one clinic to another in the hope of securing novelty in treatment if not recovery of health.

A fatal defect in the present loose inethod of caring for our sick poor is the overlapping of the institutions devoted to their care. A glance at the map of Philadelphia, for example, shows that the various dispensaries are not placed with any view to the needs of the various sections of the city. Indeed, most of them are in the older part of the city, between the Delaware and Schuylkill rivers. At one point there are five dispensaries within a radius of two blocks, while in other parts of the city large territories are entirely without any such facilities. It is, of course, almost impossible in districting a city to eliminate organizations which are already established. Much can, however, be done to prevent unnecessary duplication in the launching of new ventures.

The most poorly-clad patient is sometimes not the most deserving recipient of charity. Patients coming to the dispensary often put on their best clothes and endeavor to appear to the best advantage when seeking medical assistance. For this reason, in making rules to regulate dispensary practice, great care should be taken not to do anything which is likely to turn away those cases which really need help but are unwilling to admit that they have been reduced to such a condition. It is generally wise to give the desired advice or treat- 
ment on the occasion of the first visit of the patient, deferring investigation, except in very flagrant cases, until the pressing necessities of the applicant have been relieved. It is thus possible, without forcing the patient to wait for treatment, to provide for all immediate needs and at the same time to prevent subsequent im position.

The work of the dispensary can undoubtedly be largely increased in usefulness by securing the aid and co-operation of other charitable agencies and extending the scope of relief far beyond the mere giving of advice and treatment. The work which has been started by the Vanderbilt Clinic in New York in its dispensary for pulmonary tuberculosis is an example of what can be accomplished by following the patients to their homes and endeavoring, through the employment of a trained nurse, to ameliorate the conditions existing there. In the same way, co-operation with the charity organizations can be made a most important factor in eliminating improper cases and in performing the greatest service to the deserving. With large numbers of organizations devoted to charitable relief, there is no necessity for anyone, no matter how poor, to go hungry or sick without receiving prompt and adequate assistance. Indeed, the greatest trouble in Philadelphia is not the lack of charitable effort, but the enormous amount of competition, duplication and overlapping.

A large share of the responsibility for existing difficulties in the dispensary situation must be laid to the physicians themselves. Men of wide reputation usually charge more than the moderate wageearner can afford to pay, and the physician who is willing to accept a very small fee is too often incompetent. Probably nothing is worse for the health of the laboring classes than the treatment so often given by the quack, who is willing to supply advice and medicine for an almost nominal fee. A few standard prescriptions are all that are needed to cover the majority of ills, and a hasty examination and still more careless diagnosis are followed by an injunction to take the contents of the bottle and come again when it is exhausted. A community of interest has even been known to exist between a physician and undertaker, which naturally aroused suspicion on the part of the patients. Is it to be wondered that attendance at a public clinic, even with the loss of time and other inconveniences which may be entailed, is often thought preferable to an office visit? The patients feel, and rightly, that the names of the proninent citizens who act [432] 
as trustees are a guarantee of the character and ability of the physicians on the staff, and it is this feeling which is so often expressed in their refusal to be treated by anyone but "the professor."

State regulation of the medical profession did away with many and serious abuses, and as the standards for admission to the profession are raised and safeguarded the problem of the dispensary will undoubtedly be lessened. Were it possible to expend a larger sum for the maintenance of our dispensaries, to provide them with the best equipment, and to give the dispensary physician a direct return for his services, requiring of him, as of all the other officers, a strict performance of duty, much could be accomplished. At the present time, the dispensary is too often considered to be merely the feeder of other departments of the hospital or college, and too little thought and care are devoted to its housing, equipment and the qualifications of the medical officers. It is just as important to keep the standard of all appointments high in dispensaries as it is in other hospital work, for even where the chief of clinic is all that he might be, an incompetent or unscrupulous assistant can do a deal of harm. While the dispensary undoubtedly is abused, and while its abuse is a favorite topic of discussion, it would seem that the benefit of these institutions to the community at large is far greater than their evil effects. Improvement must come through intelligent direction on the part of those responsible for their management, conscientious and unselfish work by the medical profession, and careful investigation of applicants for relief. The dispensary is here and is here to stay. The problem is simply so to direct our medical charities that the greatest amount of good may be accomplished with the least possible waste.

FRANKLIN B. KIRKBRIDF.

Philadelphia. 